\title{
An Electronically Reconfigurable Patch Antenna Design for Polarization Diversity with Fixed Resonant Frequency
}

\author{
Mohamed Nasrun OSMAN ${ }^{1}$, Mohamad Kamal A. RAHIM ${ }^{1}$, Peter GARDNER ${ }^{2}$, \\ Mohamad Rijal HAMID ${ }^{1}$, Mohd Fairus MOHD YUSOFF', Huda A. MAJID ${ }^{l}$ \\ ${ }^{1}$ Communication Engineering Dept., Faculty of Electrical Engineering, Universiti Teknologi Malaysia, \\ 81310 Skudai, Johor, Malaysia \\ ${ }^{2}$ School of Electronic, Electrical and Computer Engineering, University of Birmingham, \\ Edgbaston, Birmingham, B15 2TT, United Kingdom. \\ mnasrun2@live.utm.my,mkamal@fke.utm.my,.p.gardner@bham.ac.uk, \\ rijal@fke.utm.my, fairus@fke.utm.my, huda2@live.utm.my
}

\begin{abstract}
In this paper, an electronically polarization reconfigurable circular patch antenna, with fixed resonant frequency and operating at Wireless Local Area Network (WLAN) frequency band (2.4-2.48 GHz,) is presented. The structure of the proposed design consists of a circular patch as a radiating element fed by a coaxial probe, cooperated with four equal-length slits etched on the edge along the $x$-axis and y-axis. A total of four switches were used and embedded across the slits at specific locations, thus controlling the length of the slits. By activating and deactivating the switches (ON and OFF) across the slits, the current on the patch is changed, thus modifying the electric field and polarization of the antenna. Consequently, the polarization excited by the proposed antenna can be switched into three types; linear polarization, left-hand circular polarization or right-hand circular polarization. This paper proposes a simple approach that enables switching the polarizations and excites at the same operating frequency. Simulated and measured results of the ideal case (using copper strip switches) and the real case (using PIN diode switches) are compared and presented to demonstrate the performance of the antenna.
\end{abstract}

\section{Keywords}

Polarization reconfigurable antenna, circular patch, slit perturbations

\section{Introduction}

Antenna is a key and critical component in wireless telecommunication systems. The evolution of the antenna has rapidly grown and been extensively investigated. It leads to a change of system requirements, hence making it more complex. Adjustments of the operating system scenario are needed in order to meet current trends and demands from end users - such as light weight and compacted devices with enhanced performance. Conventional antenna may face restrictions and limitations to adapt to the new adjustments, due to their characteristics of being fixed and inflexible. One solution to overcome this restriction is the use of reconfigurable antenna.

Reconfigurable antennas, or multi-functional antennas, have recently become quite an active and important topic of research all over the globe. This is due to the fact that the characteristics and properties of the reconfigurable antenna - such as operating frequency/bandwidth, far-field radiation pattern and polarization [1] - can be altered dynamically using external control, hence providing additional functionality and versatility to the systems. Flexibility and reconfigurability features could result in the adaptability of the antenna to address complex system requirements and new specifications. Furthermore, through this concept, the number of components, sizes and hardware complexities could be reduced [2] - hence the cost would be more economically efficient. These benefits would render reconfigurable antennas to become a highly desired feature in modern radio-frequency (RF) systems for wireless and satellite communications.

Reconfigurability can be achieved in different ways, such as through deliberate modification of the antenna physical structure, radiating edge and feeding network. These changes will alter the current flows and distributions on the antenna structure, hence modifying the performance characteristics. To achieve this reconfigurability feature, mechanical [3], optical (photoconducting switches) [4] or electronic (RF switching devices) [5] switches can be used. Among these types of switches, RF PIN diodes and RF MEMS are typical components used in designing the reconfigurable antenna. The PIN diode needs less complicated biasing components, and the lower cost results in it becoming a more popular choice amongst researchers. Even though PIN diodes also have a few drawbacks, such as high insertion loss and lower efficiency, the simplicity in biasing is a key criterion for the selection. The equivalent circuit of the PIN diode for forward bias and reverse bias is shown in Fig. 1. 


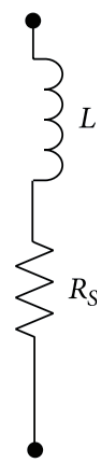

(a)

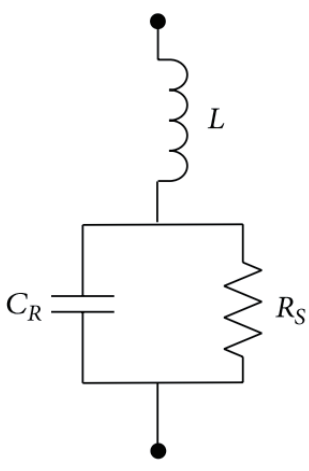

(b)
Fig. 1. PIN diode equivalent circuit. (a) forward bias; (b) reverse bias.

Recently, polarization reconfigurable antennas, which can incorporate and offer various polarizations from a single antenna, have attracted considerable attention. This is because the antenna has the ability to reduce the multipath fading [7], and the realization of frequency re-use [8]. In addition, this type of antenna is experimentally proven to improve the capacity offered in the multiple-input-multiple-output (MIMO) systems [9], [10]. For instance, the polarization reconfigurable antenna might take place between linear polarization (LP) and circular polarization (CP), between orthogonal LPs [11], [12], or between lefthand (LHCP) and right-hand circular polarization (RHCP) [13], [14]. Ideally, the main goals in designing reconfigurable antennas are to have the characteristics to be separable and independent. This is because the major challenge to achieve this kind of reconfigurability is to accomplish, without significant changes, on the frequency response and impedance matching. Therefore, careful design approaches are required in order to achieve this feature.

A few papers on the polarization reconfigurable antenna between LP and CP are reported in the literature. Reconfigurable polarization is achieved in [15], through the control of two crossing diagonal slots on the square patch. A similar technique is also used in [16]. In [17], the authors incorporated PIN diodes on the inset of the U-shaped slotline. However, the design required switchable matching stubs in order to obtain good reflection coefficient, which adds more size and complexity to the structure. Furthermore, reference [18] proposed an interesting design approach to achieve polarization reconfigurability features by creating loop slots in the ground plane. The switches were embedded on every slot of the ground plane, which altered the desired polarization sense. Even though the proposed solutions [16-18] managed to obtain a polarization reconfigurable antenna, however the changes of the polarization sense were excited at a different resonant frequency.

Hence, this paper proposes polarization reconfigurable antenna with fixed operating frequency. Details of the design, development and analysis of the polarization reconfigurable circular patch antenna with switchable slit length are presented. Two pairs of slits were located at the edge of the circular radiating patch, positioned on the $x$-axis and $y$ axis. The polarization reconfigurability feature of the an- tenna was executed by placing four switches at specific positions across the slits. The change of the state of the switches consequently alters the length of the slit, hence creating a length difference between the slit in the $x$-axis and the $y$-axis. This, accordingly, will determine the types of polarization excited by the antenna - either LHCP, RHCP or LP. Interestingly, all types of polarization senses produced are operated at the same resonant frequency.

Work done in [19] proposed quite a similar approach. However, the polarization was only able to be reconfigured between LHCP and RHCP, without consideration made for the LP. Despite that, the biasing technique applied in this paper is much simpler and requires smaller dimensions.

This manuscript is divided into two main sections based on the type of switch adopted: "Design A" (ideal diode) and "Design B" (PIN diode). The simulated and measured results for both designs are presented, compared and analyzed.

\section{Stage 1: Proof of Concept (Copper Strips)}

In this section, the initial stage of the design started with the employment of ideal switch. The ideal switch is represented by copper strips or metal pins, with dimensions of $1 \mathrm{~mm} \times 1 \mathrm{~mm}$. The presence of the copper strips indicates the switch in the 'ON' state, meanwhile the absence denotes the 'OFF' state condition.

\subsection{Antenna Geometry and Operation}

The schematic geometry of the proposed antenna is illustrated in Fig. 2. This consists of a circular patch with radius of $r$ on the finite fully grounded Taconic RF-35 substrate (dimensions of $L \times W$ in $\mathrm{mm}$ ) with a dielectric constant, $\varepsilon_{r}$ of 3.52 , thickness, $h$ of $1.52 \mathrm{~mm}$ and tangent loss, $\tan \delta$ of 0.0018 . Four slits, which have a length of $L_{s} \mathrm{~mm}$ and width of $W_{s} \mathrm{~mm}$ are etched at the corner of the circular patch, located along the $x$-axis and $y$-axis of the structure with $90^{\circ}$ apart from each other. Each slit will have a switch located across it, thus altering the length of the slits. As shown in Fig. 2, the switches are placed at the distance of $L_{p}$ from the center of the patch. The location of the switch is crucial as it determines the optimum result for the axial ratio. The feed location is positioned diagonally and is fed from the back of the structure through subminiature (SMA) probe. Parameter $d$ is optimized to achieve good impedance matching.

The design procedure generally started with determining the value of unloaded $Q_{o}$ of the patch, which depends on the radius $r$, thickness of the substrate $h$, and the dielectric constant $\varepsilon_{r}$. By using (1), the value of slit perturbation is determined [20].

$$
\left|\frac{\Delta S}{S}\right|=\frac{1}{1.841 Q_{0}}
$$


where $S$ is area of patch and $\Delta S$ is the area of slit perturbation. Then, the dimension of the slit is optimized using parameter sweep in order to obtain good circular polarization.

The approach and mechanism of the proposed antenna can be explained using the cavity model method. Due to the diagonal feeding on the structure and perturbation segments, the two near degenerated orthogonal resonant modes $\mathrm{TM}_{01}$ and $\mathrm{TM}_{10}$ are excited simultaneously. The existence of the perturbation slits will drive the surface current at the edge of the structure to move along it. The lengthened path is only affected to the current travel in the perpendicular direction to the $L_{s}$. However, from the parallel direction, the small width, $W_{s}$ of the perturbation slits will slightly affect the current that is coming from that route. For example, when the pair of slits is cut on the $x$-axis of the patch, only $\mathrm{TM}_{01}$ mode will be affected without giving much effect on the $\mathrm{TM}_{10}$ mode, and vice versa.

Due to the presence of the copper strips, the slit length will be shortened, thereby causing an effective surface current to flow across it (shortest distance) instead of travelling around the slits. Consequently, the length difference between the slit on the $x$-axis and on the $y$-axis will provide the phase delay between both orthogonal resonant modes. At a specific length difference, the two orthogonal degenerated resonant modes will have the same amplitude and in-phase quadrature, which the $\mathrm{CP}$ is excited. Meanwhile, LP is excited when two switches on the $x$-axis and $y$-axis are $\mathrm{ON}$, which means no phase difference between both orthogonal resonant modes.

Overall, this proposed antenna works in three polarization modes; namely LHCP, RHCP and LP. The type of excited polarization depends on the configurations of four switches. The switching conditions of all switches, with the respected modes, are tabulated in Tab. 1. The other configurations are not presented, as they provide the same response and redundancy results due to the geometry symmetry. Fig. 3 shows the physical structure used in the simulation, and the photograph of the prototype is shown in Fig. 4.

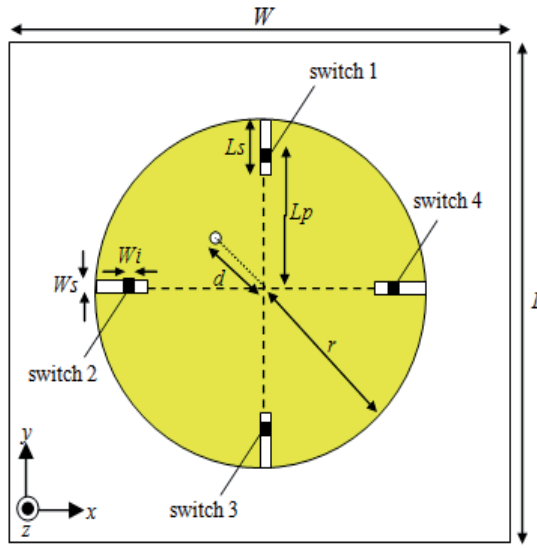

(a)

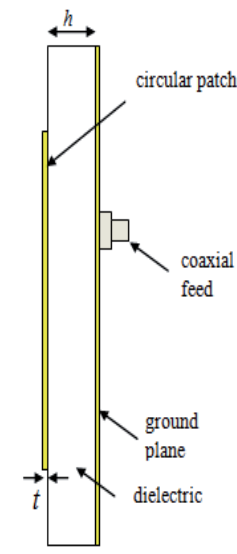

(b)
Fig. 2. Geometry of the proposed antenna: (a) front view; (b) side view.

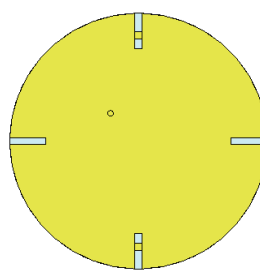

(a)

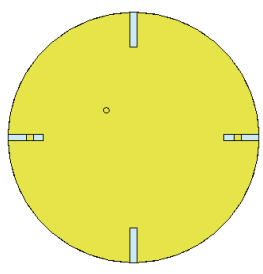

(b)

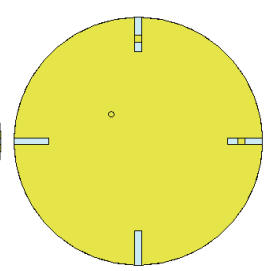

(c)
Fig. 3. The physical structure of the proposed antenna used in the simulation: (a) C1-LHCP; (b) C2-RHCP; (c) C3-LP.

\begin{tabular}{|c|c|c|c|c|c|}
\hline \multirow{2}{*}{ Configuration } & \multicolumn{4}{|c|}{ State of switch } & \multirow{2}{*}{$\begin{array}{c}\text { Polarization } \\
\text { mode }\end{array}$} \\
\cline { 2 - 5 } & SW1 & SW2 & SW3 & SW4 & OHCP \\
\hline C1-LHCP & ON & OFF & ON & OFF & LH \\
\hline C2-RHCP & OFF & ON & OFF & ON & RHCP \\
\hline C3-LP & ON & ON & OFF & OFF & LP \\
\hline
\end{tabular}

Tab. 1. Switching configurations of the proposed antenna.

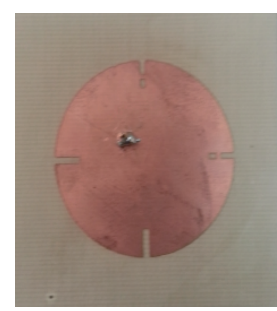

(a)

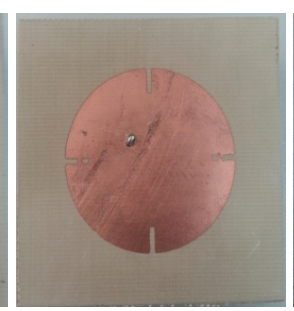

(b)

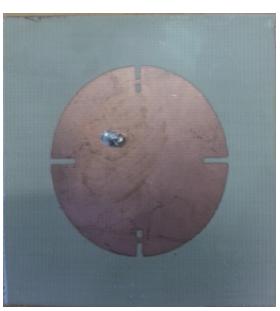

(c)
Fig. 4. Front view photograph of fabricated antenna prototypes. (a) C1-LHCP. (b) C2-RHCP. (c) C3-LP.

\subsection{Result and Analysis of the Proposed Antenna}

The prototype of the antenna is tested and analyzed. S-parameters and far-field test is measured using a Rohde \& Schwartz ZVL network analyzer and in an anechoic chamber, respectively. The simulation is carried out using Computer Simulation Technology (CST) Microwave Studio full wave simulator.

Figure 5 shows the comparison between simulated and measured reflection coefficient of the proposed antenna for all switch configurations. It can clearly be seen that for C1-LHCP and C2-RHCP, the two degenerated resonant modes $\left(\mathrm{TM}_{01}\right.$ and $\left.\mathrm{TM}_{10}\right)$ are excited with close frequency at $2.45 \mathrm{GHz} / 2.49 \mathrm{GHz}$ and $2.45 \mathrm{GHz} / 2.50 \mathrm{GHz}$, respectively. Meanwhile, the resonant frequency for C3-LP is $2.48 \mathrm{GHz}$. The measured $-10 \mathrm{~dB}$ bandwidths $(\mathrm{BW})$ of $\mathrm{S}_{11}$ are $71 \mathrm{MHz}(2.438 \div 2.509 \mathrm{GHz}), 84 \mathrm{MHz}(2.437 \mathrm{GHz}$ to $2.521 \mathrm{GHz})$ and $43 \mathrm{MHz}(2.462 \div 2.505 \mathrm{GHz})$ for C1-LHCP, C2-RHCP and C3-LP, respectively. A good impedance matching is achieved for all configurations. It is observed that the measured center frequency is slightly higher than the simulated one. This frequency shift may be due to fabrication uncertainty.

The simulated and measured result of the axial ratio of two CP operations is shown in Fig. 6. For C1-LHCP, the 


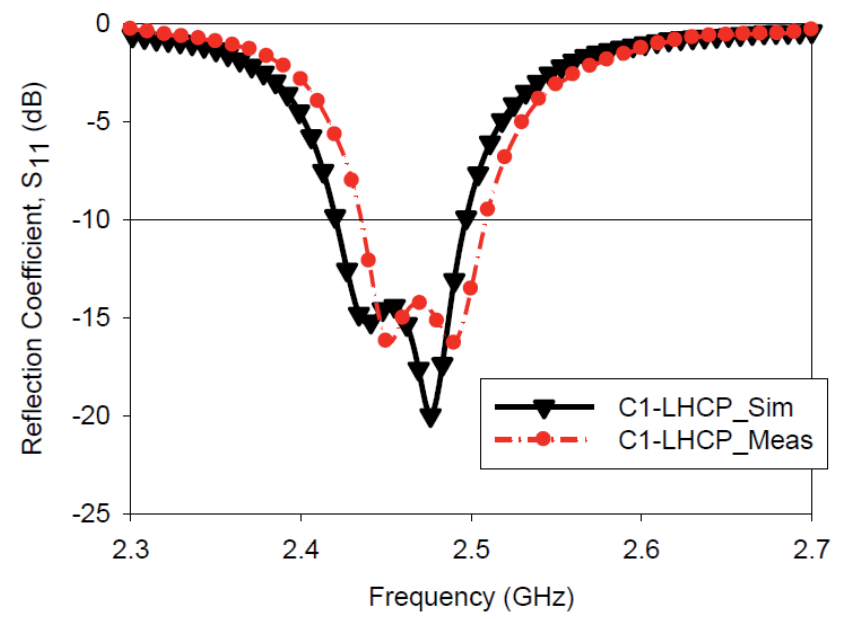

(a)

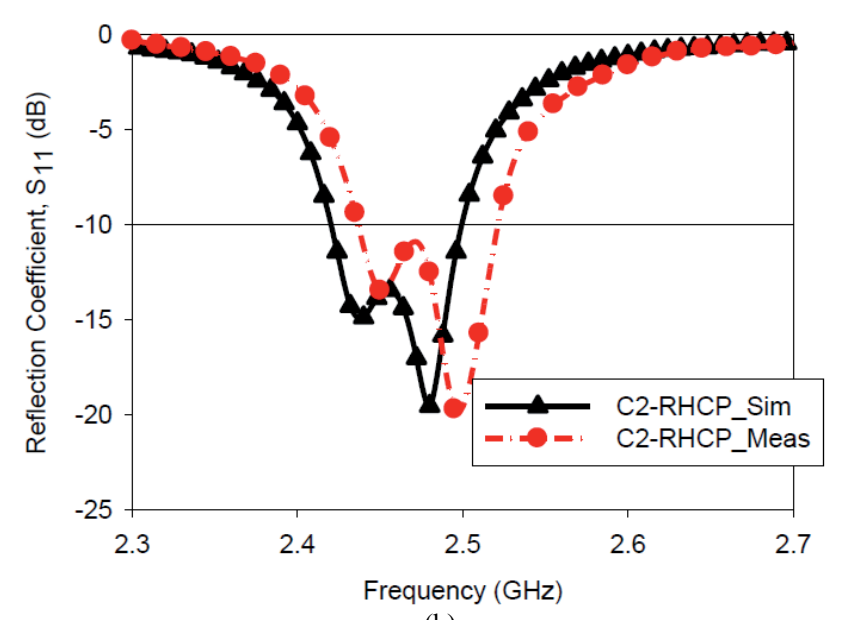

(b)

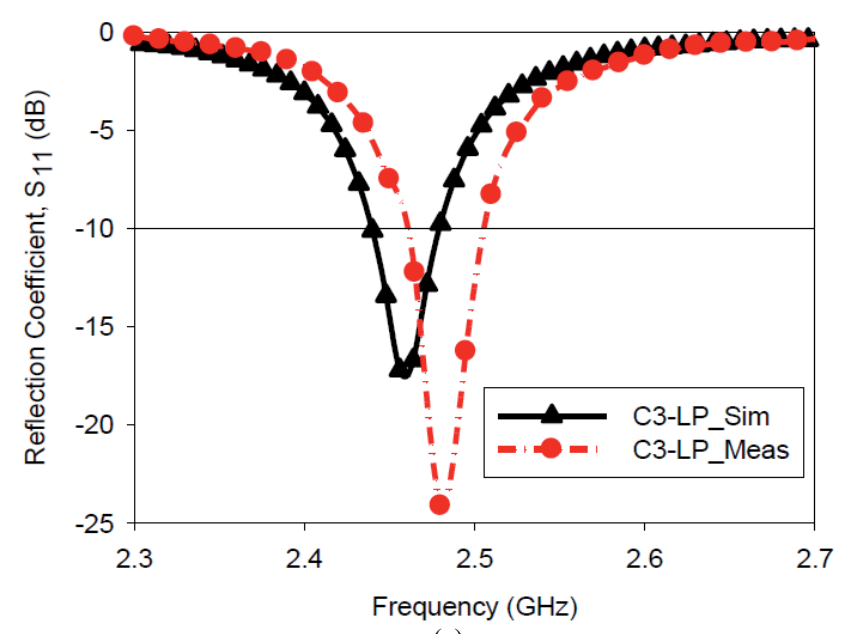

(c)

Fig. 5. Comparison of simulated and measured reflection coefficient of the proposed antenna: (a) C1-LHCP; (b) C2-RHCP; (c) C3-LP.

measured $3 \mathrm{~dB}$ axial ratio bandwidth is $19 \mathrm{MHz}$ $(2.456 \div 2.475 \mathrm{GHz})$, or $0.77 \%$ with respect to the center frequency of $2.468 \mathrm{GHz}$. In addition, the BWCP for C2-RHCP is $18 \mathrm{MHz}(2.463 \div 2.481 \mathrm{GHz})$, or $0.73 \%$ with respect to frequency of $2.472 \mathrm{GHz}$. The phenomenon variance of the reflection coefficient result leads to the axial

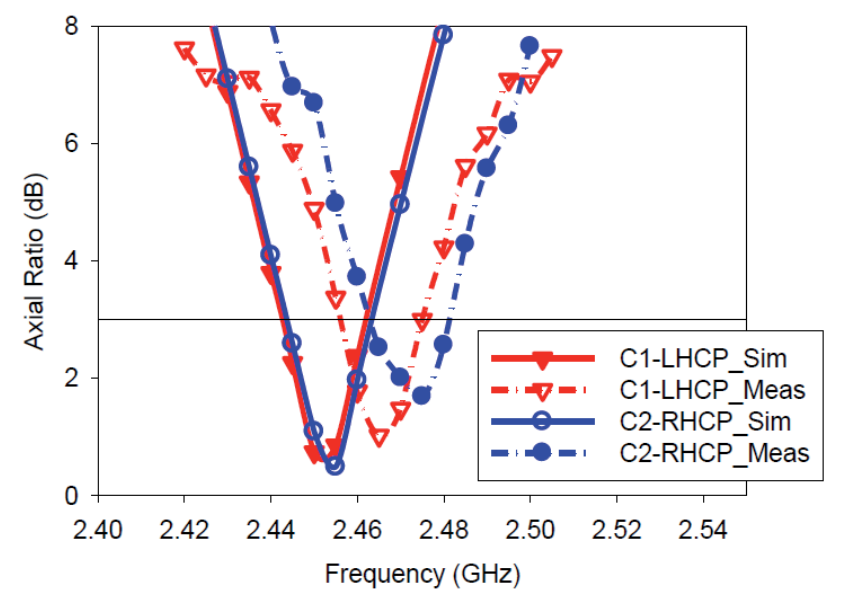

Fig. 6. Simulated and measured axial ratio.
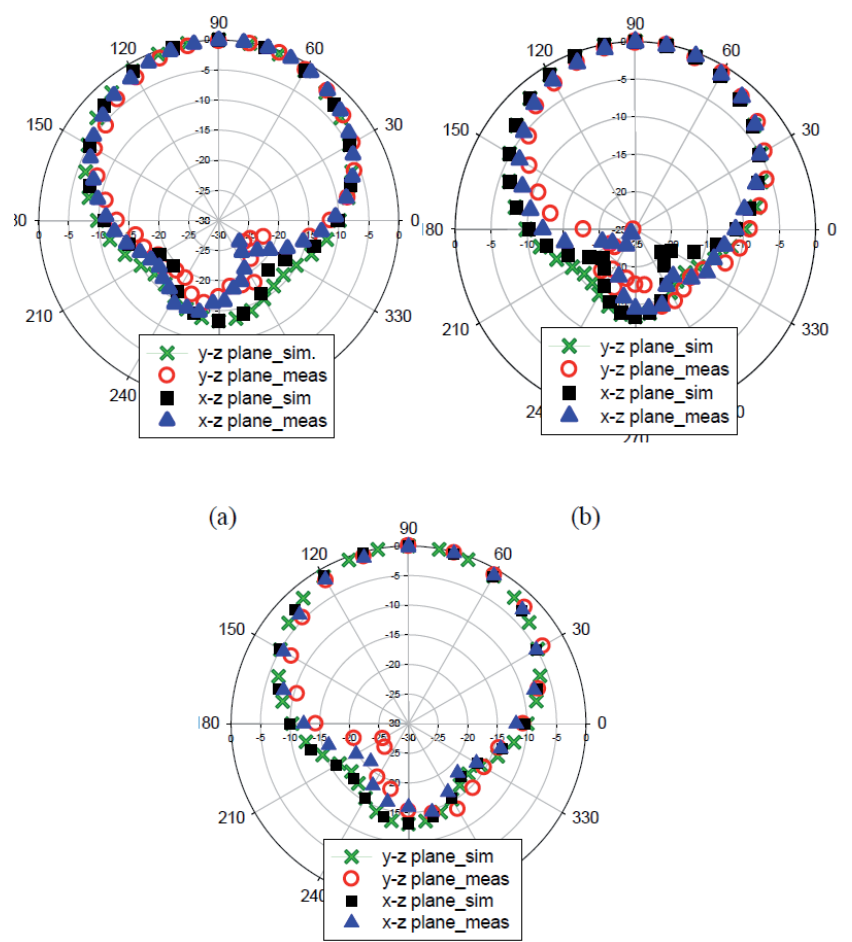

(c)

Fig. 7. Simulated and measured normalized far-field radiation pattern at frequency of $2.47 \mathrm{GHz}$ : (a) C1-LHCP; (b) C2-RHCP; (c) C3-LP.

ratio to be shifted as well. The far-field radiation of the proposed antenna is investigated. Figure 7 presents the simulated and measured normalized radiation pattern $(y-z$ plane and $x-z$ plane) at $2.47 \mathrm{GHz}$. Good radiation pattern performance, with broadside form, is achieved for all types of polarization modes at the respective center frequency.

\section{Stage 2: Antenna Design and Operation; Realization of Active Switches (PIN Diodes)}

In this section, the copper strips are replaced by RF PIN diode. In this design, the RF PIN diode being used is 
Infineon BAR 50-02L. For activating and deactivating the diodes, the antenna structure is modified by integrating a biasing circuit into the structure. To activate the diode, forward bias current is supplied to the ON-state, and the diode is left unbiased for the OFF state condition.

\subsection{Modified Structure of the Antenna with Integrated Biasing Circuit}

Figure 8 illustrates the antenna structure with modifications, including biased line and lump elements for the purpose of DC biasing. To accommodate the biasing network, minor adjustment was made on the design and resimulation was done using the CST software in order to obtain the optimum results. The comparison of the dimension dissimilarity, between without biasing network (design A) and with consideration of biasing network (design B), is tabulated in Tab. 2.

In this structure, L-shape narrow slots with width of $W_{b}=0.3 \mathrm{~mm}$ and a length of $9 \mathrm{~mm}\left(L_{b 1}+L_{b 2}\right)$ are created to separate between the positive and negative areas of the DC voltage supply. Additional lump elements, RF capacitors and RF inductors are introduced into the design for a specific purpose. Five RF chokes inductors are placed between the radiator and biased wire to improve the isolation between RF current and DC supply [7]. The value of all inductors is $27 \mathrm{nH}$. Furthermore, considering the effect of the narrow slots, twelve DC block capacitors of $100 \mathrm{pF}$ are mounted across it in order to preserve the continuity of the RF current across the radiator.

The cathodes of the diodes are connected to the four small copper areas and supplied with negative DC voltage. Meanwhile, the anodes of the diodes, which are soldered to the remaining copper region on the circular patch, are connected to the positive terminal of the positive DC battery. The DC is directly supplied using copper wire to the radiator through a via-hole and small circle slots created on the ground plane. The circle slots, with a diameter of $L_{c}$ are introduced to provide separation of DC voltage. This technique is taken to avoid the presence of the biased wire from

\begin{tabular}{|c|c|c|c|c|c|}
\hline \multirow{2}{*}{ Parameter } & \multicolumn{2}{|c|}{ Value (mm) } & \multirow{2}{*}{ Parameter } & \multicolumn{2}{|c|}{ Value (mm) } \\
\cline { 2 - 3 } & $\mathbf{A}$ & $\mathbf{B}$ & & $\mathbf{A}$ & $\mathbf{B}$ \\
\hline$L$ & 55 & 55 & $W_{b}$ & - & 0.3 \\
\hline$W$ & 55 & 55 & $W_{i}$ & 1 & - \\
\hline$h$ & 1.524 & 1.524 & $L_{S}$ & 5 & 5 \\
\hline$t$ & 0.035 & 0.035 & $L_{p}$ & 15.3 & 17 \\
\hline$d$ & 5.5 & 5.5 & $L_{b 1}$ & - & 5 \\
\hline$r$ & 17.9 & 17.9 & $L_{b 2}$ & - & 4 \\
\hline$W_{S}$ & 1 & 1 & $L_{c}$ & - & 4 \\
\hline
\end{tabular}

Tab. 2. Dimension of the designed antennas (Design A and Design B).
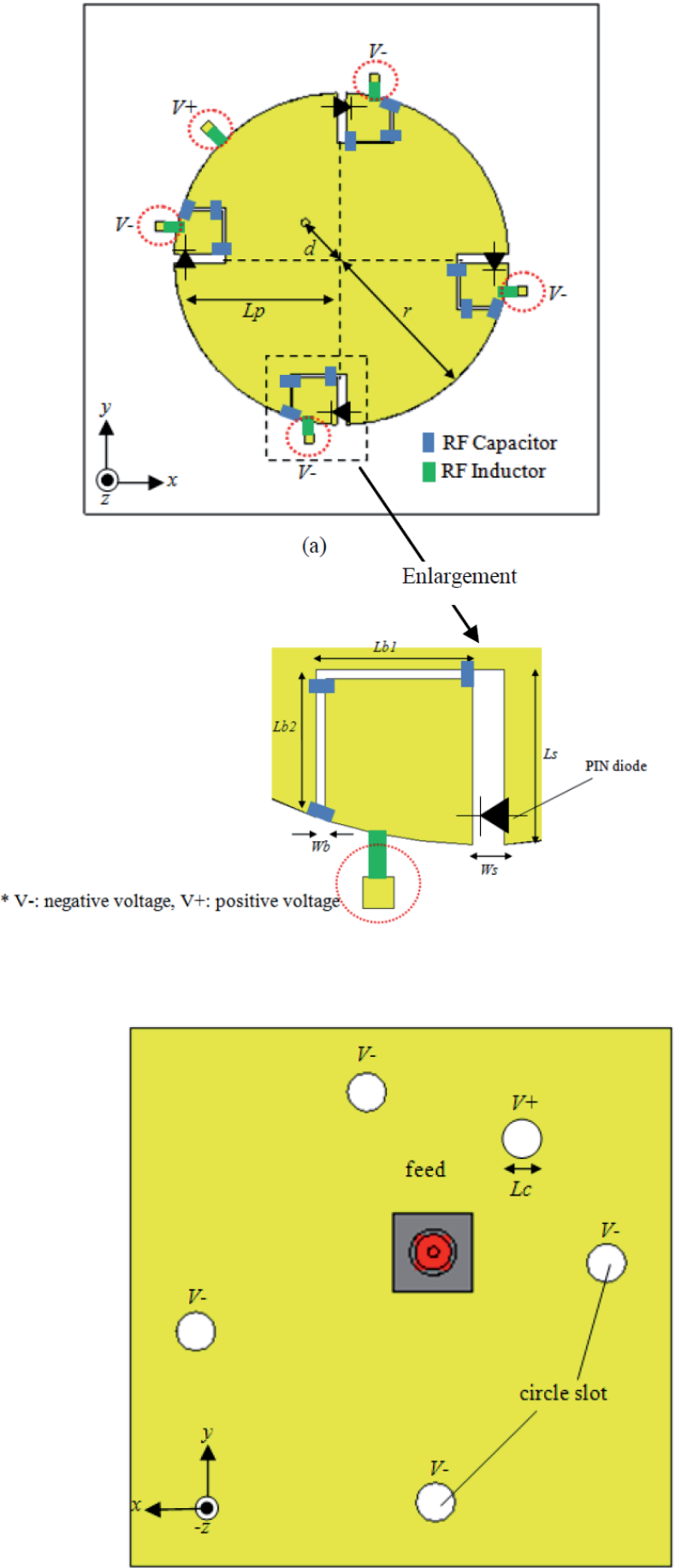

(b)

Fig. 8. Geometry of the proposed antenna with the integration of biasing mechanism: (a) front view, (b) back view.

interrupting the antennas far-field radiation pattern. In the meantime, the wire is terminated at the small square copper located outside the circular patch. For the activation of the diodes, the external switching control board is constructed. The switching board is composed of copper wire, 9V DC battery, a dip switch to control the biasing and the resistor for current limitation. The resistors with a value of $100 \Omega$ are chosen so that the forward biased current $90 \mathrm{~mA}$ is obtained (ON-state) and left unbiased in the OFF-state condition. The photograph of the fabricated antenna is shown in Fig. 9. 


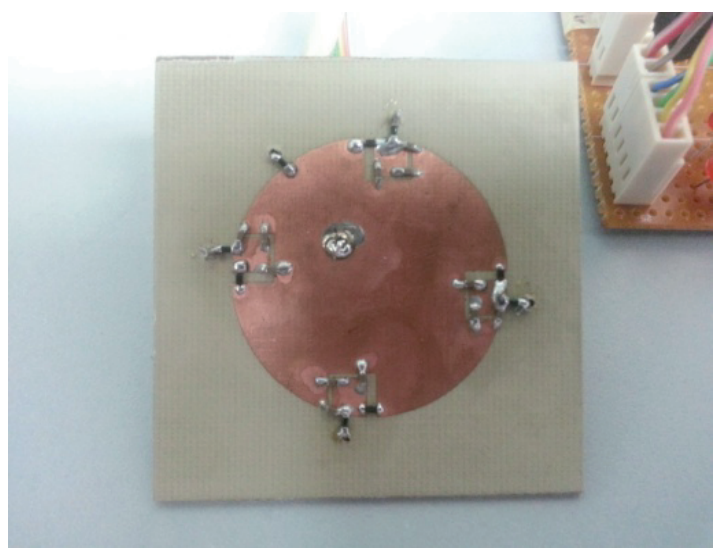

(a)

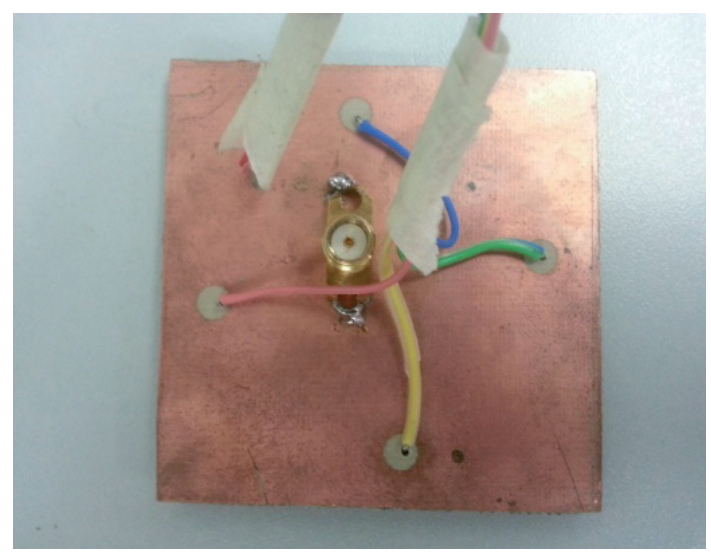

(b)

Fig. 9. Photograph of fabricated antenna prototypes: (a) front view, (b) back view.

\subsection{Results and Analysis of the Modified Antenna}

For accurate simulation results, the PIN diode (Infineon BAR 50-02L) was included in the design and simulated using CST. This step was done by the utilization of touchstone block that contains $s 2 p$ file which can be obtained from the manufacturer. The touchstone file consists of the information s-parameter of the diode for the $\mathrm{ON}$ and OFF state condition.

The optimized antenna was measured using the similar equipment and set up used for the measurement of the ideal diode. The simulated and measured reflection coefficients of the modified structure for all switch configurations are presented in Fig. 10. Good measured impedance matching was achieved for C3-LP, with $-10 \mathrm{~dB}$ reflection coefficient bandwidth is in the frequency range of 2.469 to $2.515 \mathrm{GHz}$, or $46 \mathrm{MHz}$.

However, the reflection coefficient for CP operations is slightly above $-10 \mathrm{~dB}$. The impedance bandwidths, based on $-10 \mathrm{~dB}$ reflection coefficient is $40 \mathrm{MHz}(2.494 \mathrm{GHz}$ to $2.534 \mathrm{GHz})$ and $48 \mathrm{MHz}(2.5 \div 2.548 \mathrm{GHz})$ for C1-LHCP and C2-RHCP, respectively.

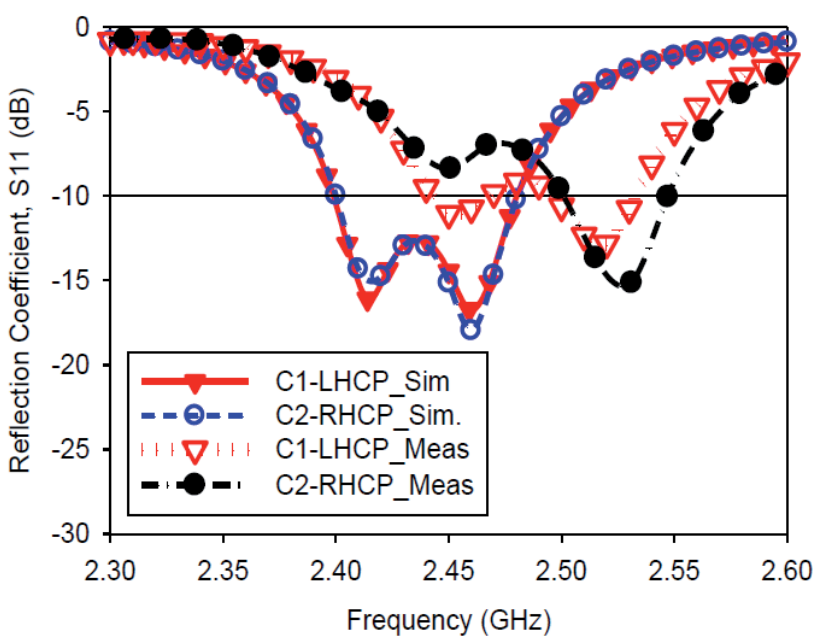

(a)

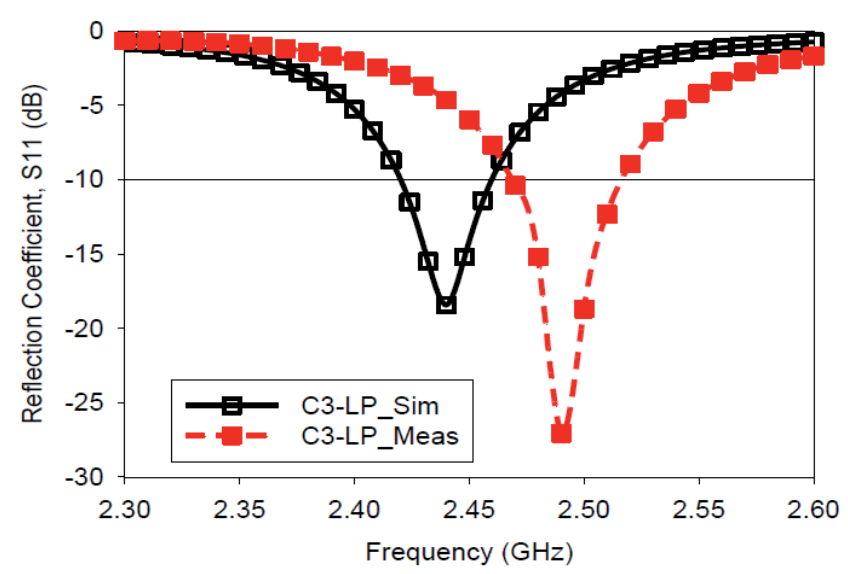

(b)

Fig. 10. Comparison between the simulated and measured reflection coefficient result of the modified structure. (a) Circular polarization. (b) C3-LP.

It can be seen that measurement is shifted to the higher frequency. It is also observed that the good impedance matching was obtained except for C2-RHCP configuration. The lowest value of the magnitude of $S_{11}$ for C2-RHCP is $-6.7 \mathrm{~dB}$ obtained at a frequency of $2.473 \mathrm{GHz}$. The slight discrepancies between simulation and measurement results could be due to fabrication tolerance, SMA port or parasitic effects from the PIN diode. As mentioned before, the position of the diode in the slits is highly crucial as it determines the axial ratio result and could affect the impedance of the antenna.

Figure 11 shows the simulated and measured results for axial ratio. The measured $\mathrm{BW}_{\mathrm{CP}}$, as referred to $3 \mathrm{~dB}$ axial ratio bandwidth, is $31 \mathrm{MHz}(2.483 \div 2.452 \mathrm{GHz})$ and $22 \mathrm{MHz}(2.474 \div 2.452 \mathrm{GHz})$ for C1-LHCP and C2-RHCP, respectively. It has to be noted that the $\mathrm{BW}_{\mathrm{CP}}$ is totally covered by the BW for linear polarization. Since the proposed antenna performs polarization reconfiguration at a single operating frequency, thus the available working bandwidth is mainly determined by $\mathrm{BW}_{\mathrm{CP}}$. Due to symmetry structure, the performances for the both $\mathrm{CP}$ operations 
are almost identical for reflection coefficient and axial ratio result, like the case of ideal diode. The frequency shifted of the reflection coefficient cause the variance between simulated and measured result for the axial ratio. This is due to the shift of the two degenerated orthogonal modes which will consequently shift the frequency of the excited $\mathrm{CP}$ mode.

The measured far-field radiation patterns in the $y-z$ plane and $x-z$ plane for all operation modes are plotted in Fig. 12. Measured results show that the antenna has a broadside radiation pattern at the resonant frequency and $3-\mathrm{dB}$ beamwidth of more than $90^{\circ}$ is obtained. In addition, the graph depicts that the proposed antenna has almost the same pattern in both planes. It is also noticed that the gain for C3-LP is higher than the CP modes. The comparison of results between design $\mathrm{A}$ and design $\mathrm{B}$ is summarized in Tab. 3 .

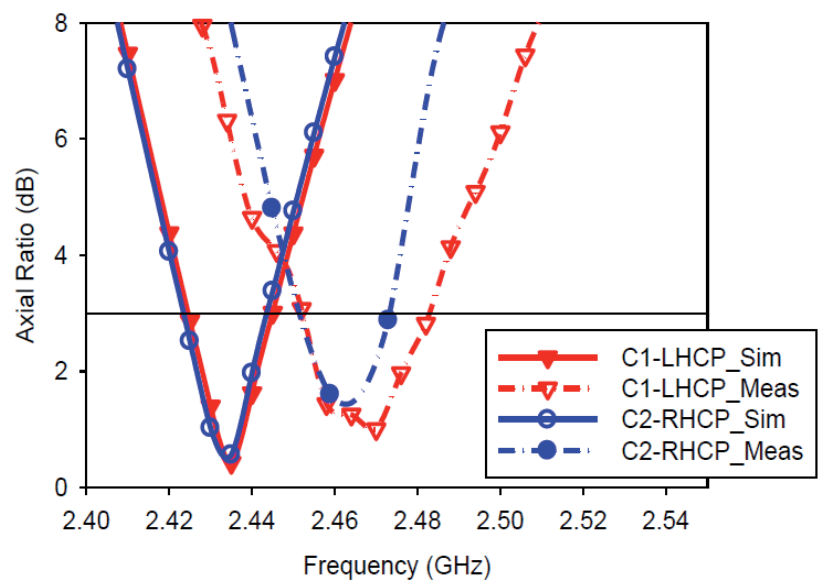

Fig. 11. Simulated and measured axial ratio of the modified structure. (a)

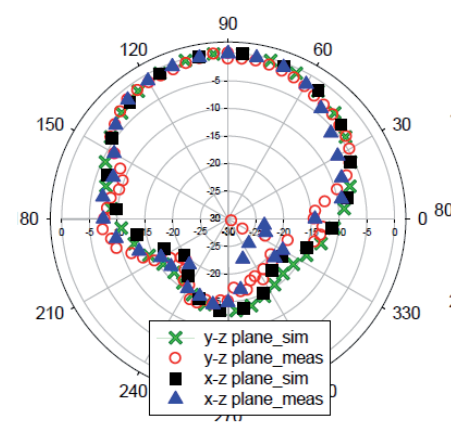

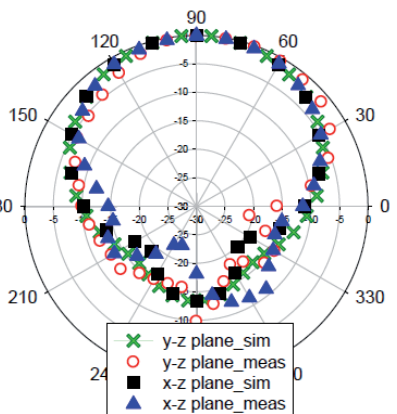

(b)

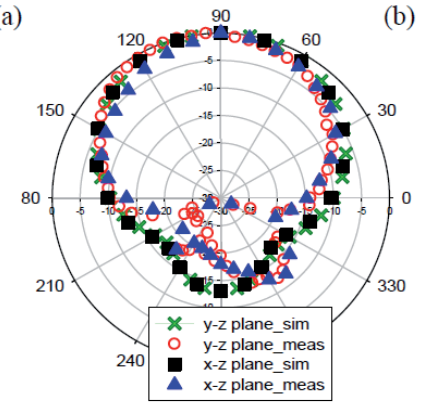

(c)

Fig. 12. Measured normalized radiation pattern of the modified structure: (a) C1-LHCP at $2.47 \mathrm{GHz}$; (b) C2-RHCP at $2.47 \mathrm{GHz}$; (c) C3-LP at $2.49 \mathrm{GHz}$.

\begin{tabular}{|c|c|c|c|c|c|c|c|}
\hline \multirow{3}{*}{ Conf. } & \multirow{3}{*}{ Polar. } & \multicolumn{2}{|c|}{ Meas. $S_{11}(\mathrm{~dB})$} & \multicolumn{4}{|c|}{$\begin{array}{c}\text { Meas. Bandwidth } \\
\text { (MHz) }\end{array}$} \\
\hline & & \multirow{2}{*}{$\begin{array}{c}\text { Design } \\
\mathrm{A}\end{array}$} & \multirow{2}{*}{$\begin{array}{c}\text { Design } \\
\text { B }\end{array}$} & \multicolumn{2}{|c|}{$\begin{array}{l}-10 \mathrm{~dB} \\
\mathrm{BW}\end{array}$} & \multicolumn{2}{|c|}{$\begin{array}{c}\text { 3-dB BW } \\
\text { (Axial } \\
\text { Ratio) } \\
\end{array}$} \\
\hline & & & & A & B & A & B \\
\hline C1-LHCP & LHCP & -16.48 & -12.60 & 71 & 40 & 19 & 31 \\
\hline C2-RHCP & RHCP & -19.83 & -15.25 & 84 & 48 & 18 & 22 \\
\hline C3-LP & LP & -24.06 & -26.62 & 43 & 46 & & \\
\hline
\end{tabular}

Tab. 3. Comparison between Design A and Design B.

\section{Conclusions}

This paper presents a simple technique to achieve polarization reconfigurable antenna, with a fixed resonant frequency, that operates within WLAN frequency band. The study begins with the use of copper strips as a switch for proof of the concept. Then, minor modifications were made on the structure in order to accommodate the employment of real switches (RF PIN diode) and switching network. Using four switches embedded across the slits, the slit length is altered, hence producing a phase difference between two degenerated orthogonal resonant modes. Consequently, depending on the switching state, the polarization excited by the proposed antenna is capable to be reconfigured between three types - LHCP, RHCP or LP - that functioned at the same operating frequency. The results of reflection coefficient, axial ratio and radiation pattern are presented and comparisons are made between all different bias conditions. The results demonstrate good impedance matching, and broadside radiation pattern. The discrepancies of the results might be due to parasitic effects of the PIN diode, or fabrication tolerance. Small in dimension, and with unique features, the proposed antenna is potentially suitable in wireless applications for limited space and multipath rich environments; such as to serve as an access point in an indoor scenario for WIFI application.

\section{Acknowledgements}

The authors thank the Ministry of Higher Education (MOHE) for supporting the research work, Research Management Centre (RMC), School of Postgraduate (SPS) and Communication Engineering Dept., Universiti Teknologi Malaysia (UTM) for the support of the research under grant no QJ13000.7123.04H38, 4L811, 05H35 and 4F360.

\section{References}

[1] BYUN, S.-B., LEE, J.-A., LIM, J.-H., YUN, T.-Y. Reconfigurable ground-slotted patch antenna using PIN diode switching. ETRI Journal, Dec. 2007, vol. 29, no. 6, p. 832-834. 
[2] KUMAR, S., GOLI, H., BASKARAN, P., ANGELA, P. P. Novel reconfigurable microstrip antenna. In IEEE $3^{\text {rd }}$ International Conference on Industrial and Information Systems. Kharagpur (India), Dec. 2008, p. 1-5, DOI: 10.1109/ICIINFS.2008.4798448

[3] RUVIO, G., AMMANN, M. J., CHEN, Z. N. Wideband reconfigurable rolled planar monopole antenna. IEEE Transactions on Antennas and Propagation, 2007, vol. 55, no. 6, p. 1760-1767. DOI: 10.1109/TAP.2007.898575

[4] PANAGAMUWA, C. J., CHAURAYA, A. C., VARDAXOGLOU, J. C. Frequency and beam reconfigurable antenna using photoconducting switches. IEEE Transactions on Antennas and Propagation, Feb. 2006, vol. 54, no. 2, p. 449-454. DOI: 10.1109/TAP.2005.863393

[5] NIKOLAOU, S., KIM, B., VRYONIDES, P. Reconfiguring antenna characteristics using PIN diodes. In The $3^{\text {rd }}$ European Conference on Antennas and Propagation EuCap2009. Berlin (Germany), 2009, p. 3748-3752.

[6] ISMAIL, M. F., A. RAHIM, M. K., MAJID, H. A. The investigation of PIN diode switch on reconfigurable antenna. In IEEE International RF and Microwave Conference RFM 2011. Seremban (Negeri Sembilan, Malaysia), December 2011, p. 234-237. DOI: 10.1109/RFM.2011.6168737

[7] FERRERO, F., LUXEY, C., JACQUEMOD, G., STARAJ, R., FUSCO, V. Polarisation-reconfigurable patch antenna. In International Workshop on Antenna Technology: Small and Smart Antennas Metamaterials and Applications IWAT 2007. Cambridge (UK), 2007, no. 1, p. 73-76. DOI: 10.1109/IWAT.2007.370083

[8] LIM, J.-H., BACK, G.-T., YUN, T.-Y. Polarization-diversity cross-shaped patch antenna for satellite-DMB systems. ETRI Journal, Apr. 2010, vol. 32, no. 2, p. 312-318. DOI: 10.4218/etrij.10.0109.0280

[9] PIAZZA, D., MOOKIAH, P., D’AMICO, M., DANDEKAR, K. R. Pattern and polarization reconfigurable circular patch for MIMO systems. In European Conference on Antennas and Propagation EuCap 2009. Berlin (Germany), 2009, p. 1047-1051.

[10] PIAZZA, D., MOOKIAH, P., D'AMICO, M., DANDEKAR, K. R. Experimental analysis of pattern and polarization reconfigurable circular patch antennas for MIMO systems. IEEE Transactions on Vehicular Technology, 2010, vol. 59, no. 5, p. 2352-2362. DOI: $10.1109 /$ TVT.2010.2043275

[11] LI, Y., ZHANG, Z., CHEN, W., FENG, Z. Polarization reconfigurable slot antenna with a novel compact CPW-to-slotline transition for WLAN application. IEEE Antennas and Wireless Propagation Letters, 2010, vol. 9, p. 252-255. DOI: 10.1109/LAWP.2010.2046006

[12] AMINI, M. H., HASSANI, H. R., NEZHAD, S. M. A. A single feed reconfigurable polarization printed monopole antenna. In European Conference on Antennas and Propagation EuCap 2012. Prague (Czech Rep.), 2012, p. 1-4. DOI: 10.1109/EuCAP.2012.6205882

[13] LAI, C.-H., HAN, T.-Y., CHEN, T.-R. Circularly-polarized reconfigurable microstrip antenna. Journal of Electromagnetic Waves and Applications, 2009, vol. 23, no. 2-3, p. 195-201. DOI: $10.1163 / 156939309787604373$

[14] WANG, C.-C., CHEN, L.-T., ROW, J.-S. Reconfigurable slot antennas with circular polarization. Progress in Electromagnetics Research Letters, 2012, vol. 34, p. 101-110. DOI:10.2528/PIERL12072410

[15] MONTI, G., CORCHIA, L., TARRICONE, L. Patch antenna with reconfigurable polarization. Progress in Electromagnetics Research C, 2009, vol. 9, p. 13-23.

[16] HYUN, D.-H., BAIK, J.-W., LEE, S. H., KIM, Y.-S. Reconfigurable microstrip antenna with polarisation diversity. Electronics Letters, 2008, vol. 44, no. 8, p. 509-511. DOI: 10.1049/el:20080125
[17] KIM, B., PAN, B., NIKOLAOU, S., KIM, Y.-S., PAPAPOLYMEROU, J., TENTZERIS, M. M. A novel single-feed circular microstrip antenna with reconfigurable polarization capability. IEEE Transactions on Antennas and Propagation, 2008, vol. 56, no. 3, p. 630-638. DOI: 10.1109/TAP.2008.916894

[18] YANG, X.-X., SHAO, B.-C., YANG, F., ELSHERBENI, A. Z., GONG, B. A polarization reconfigurable patch antenna with loop slots on the ground plane. IEEE Antennas and Wireless Propagation Letters, 2012, vol. 11, p. 69-72. DOI: 10.1109/LAWP.2011.2182595

[19] CHEN, Y. B., CHEN, T. B., JIAO, Y. C., ZHANG, F. S. A reconfigurable microstrip antenna for switchable polarization. Journal of Electromagnetic Waves and Applications, 2006, vol. 20, no. 10, p. 1391-1398. DOI: 10.1163/156939306779276820

[20] GARG, R., BHARTIA, P., BAHL, I., ITTIPIBOON, A. Microstrip Antenna Design Handbook, Artech House Publishers, January 2001 .

\section{About the Authors ...}

Mohamed Nasrun OSMAN was born in November 1987. He received his Electrical Engineering degree major telecommunication from Universiti Teknologi Malaysia in 2010. He is currently working towards his $\mathrm{PhD}$ degree in Electrical Engineering at the same university. His research interests include reconfigurable antenna design, RF design and wireless MIMO system.

Mohamad Kamal A RAHIM was born in Alor Star Kedah Malaysia on 3rd November, 1964. He received the B Eng degree in Electrical and Electronic Engineering from University of Strathclyde, UK in 1987. He obtained his Master Engineering from University of New South Wales, Australia in 1992. He graduated his $\mathrm{PhD}$ in 2003 from University of Birmingham, U.K., in the field of Wideband Active Antenna. From 1992 to 1999, he was a lecturer at the Faculty of Electrical Engineering, Universiti Teknologi Malaysia. From 2005 to 2007, he was a senior lecturer at the Department of Communication Engineering, Faculty of Electrical Engineering, Universiti Teknologi Malaysia. He is now a Professor at Universiti Teknologi, Malaysia. His research interest includes the design of active and passive antennas, dielectric resonator antennas, microstrip antennas, reflect-array antennas, electromagnetic band gap (EBG), artificial magnetic conductors (AMC), left-handed metamaterials and computer aided design for antennas.

Peter GARDNER graduated in Physics from the University of Oxford in 1980 with first class honors. He gained eight years of industrial experience in research and development of active microwave components for Ferranti International, Poynton, Cheshire and later as an independent consultant. He obtained his MSc in 1990 and PhD in 1992. He joined the School of Electronic and Electrical Engineering at Birmingham in 1994, as a lecturer, and currently is a Head of School for School of Electronic, Electrical and Computer Engineering. His research interests include active and adaptive antenna, microwave amplifier, transmitter linearization and micromachine antennas.

Mohamad Rijal HAMID received the M.Sc. degrees in Communication Engineering from the Universiti Teknologi 
Malaysia, Johor Bahru, Malaysia, in 2001 and the $\mathrm{PhD}$ Degree at the University of Birmingham, Birmingham, United Kingdom. He has been with Universiti Teknologi Malaysia at the Faculty of Electrical Engineering, UTM since 1999. Currently his position is a Senior Lecturer. His major research interest is reconfigurable antenna design for multimode wireless applications.

Mohd Fairus MOHD YUSOFF is a graduate faculty member of the Faculty of Electrical Engineering, UTM. He joined UTM in 2002 as a Tutor. He received his Bachelor in Engineering (Electrical-Telecommunication) in 2002 and Master of Electrical Engineering (Electrical-Electronics and Telecommunications) in 2005 from Universiti
Teknologi Malaysia. He obtained his $\mathrm{PhD}$ in 2012 from University of Rennes 1, France in area of Signal Processing and Telecommunication. His main research interest and areas is antenna design, millimeter waves and microwave devices.

Huda A. MAJID obtained his first degree in Electrical Engineering majoring Telecommunication in 2007 and his M.Sc in 2010 from Universiti Teknologi Malaysia, Johor Bahru. He received his $\mathrm{PhD}$ degree from the same institution in 2013. His research interest includes design of metamaterials, reconfigurable antennas, RF and microwave. He is currently working as a Postdoctoral Research Fellow since January 2014. 